\title{
DETERMINAÇÃO DO MÓDULO DE ELASTICIDADE EM MADEIRA LAMINADA COLADA POR MEIO DE ENSAIO NÃO DESTRUTIVO ("STRESS WAVE TIMER”)
}

\author{
Alexsandro Bayestorff da Cunha² e Jorge Luis Monteiro de Matos ${ }^{3}$
}

\begin{abstract}
RESUMO - As vigas estruturais de madeira são formas racionais do emprego da madeira na construção de estruturas, sendo obtidas pela associação de peças serradas e permitindo a utilização de tábuas com seções e comprimentos variados, além de combinações com madeira de qualidade diferenciada. Para atingir a resistência máxima de uma viga de madeira laminada colada, pode-se utilizar a classificação mecânica das peças por meio dinâmico. O objetivo deste estudo foi estabelecer correlação entre os métodos estático e dinâmico de classificação de vigas de madeira laminada. O trabalho foi desenvolvido com o emprego de peças de madeira serrada de Pinus taeda e adesivo resorcina fenolformaldeído. O processo de fabricação das vigas envolveu a classificação das peças, usinagem de emendas, formação das lamelas, montagem e prensagem das vigas. Já os ensaios envolveram a determinação do módulo de elasticidade por meio do "stress wave method" e de uma máquina universal de ensaios. Os resultados foram analisados pela análise de regressão do estabelecimento da equação de ajuste de correlação. O sistema de classificação visual utilizado na seleção de peças foi insuficiente para se atingirem os valores máximos de módulo de elasticidade; o posicionamento correto das lamelas por meio do método dinâmico de classificação teve como consequência direta o aumento do módulo de elasticidade da viga, e houve baixa correlação entre as formas de obtenção do módulo de elasticidade das vigas, não sendo possível a elaboração de equação adequada entre os métodos testados.
\end{abstract}

Palavras-chave: Madeira laminada colada, Classificação de vigas e “Stress wave method”.

\section{DETERMINATION OF THE ELASTICITY MODULE IN GLULAM THROUGH A NON DESTRUCTIVE ASSAY (STRESS WAVE TIMER)}

\begin{abstract}
Structural wood beams are a form of rational use of wood in construction of structures; being obtained through the association of sawn pieces, and allowing the use of boards with various sections and lengths, as well as combinations with a differentiated quality wood. To achieve the maximum strength of a Glulam, you can use the mechanical classification of pieces by means of the dynamic system. The goal of the study was to establish a correlation between the static and dynamic methods of classification of glulam beams. The work was developed with the use of pieces of saw wood of Pinus taeda and adhesive phenol resorcinol formaldehyde. The beam fabrication process concerned the classification of the pieces, correction machining and lamella formation, as well as the assemblage and pressurization of the beams. The assays, nevertheless, involved the determination of the elasticity module by means of the stress wave method and a universal machine of assays. The results were analyzed by means of the regression analysis for the establishment of the equation of adjusting the correlation. The classification system used to select pieces was insufficient to obtain the maximum values of the modulus of elasticity; the correct positioning of lamellas by means of the method of dynamic classification had as a direct consequence the increase of the elasticity module of beam and there was a low correlation between the methods of obtaining the modulus of elasticity of the beams, it is not possible for the development of an appropriate equation of correlation between the methods tested.
\end{abstract}

Keywords: Glulam, Classification of beams and Stress wave method.

\footnotetext{
${ }^{1}$ Recebido em 05.08.2008 e aceito para publicação em 14.10.2009.

${ }^{2}$ Universidade do Estado de Santa Catarina (UDESC), Brasil. E-mail: <a2abc@cav.udesc.br>.

${ }^{3}$ Universidade Federal do Paraná, UFPR, Brasil.
} 


\section{INTRODUÇÃO}

A madeira como material de construção oferece vantagens que superam outros materiais tradicionais como aço, concreto e alvenaria. Entre as potencialidades da madeira, destacam-se o baixo peso em relação a uma alta resistência, pouco consumo energético para o seu processamento, capacidade para suportar sobrecargas de curta duração; boa resistência ao fogo, quando comparada com as estruturas de aço e de mais estruturas metálicas; vantagens econômicas, quando seu custo inicial é analisado, levando-se em conta um longo prazo de utilização do material.

De acordo com as características supracitadas, surgiram em 1906, através do carpinteiro suíço Otto Hetzer, as vigas estruturais de Madeira Laminada Colada (MLC), as quais eram confeccionadas com cola de caseína; as vigas apresentavam-se como uma forma racional de emprego da madeira na construção de estruturas, obtida pela associação de peças. Essa técnica facilita a construção de grandes estruturas com dimensões e formas variadas, limitadas apenas ao local onde serão fabricadas e ao meio de transporte utilizado. Para tanto, a confecção de vigas estruturais de madeira laminada colada é limitada pela qualidade da matériaprima disponível no mercado, pelo seu alto preço e pela falta de conhecimento e investimento em equipamentos de classificação de peças que proporcionam o aumento dos coeficientes de resistência da viga de forma significativa.

Tradicionalmente, a caracterização das propriedades da madeira é feita por meio da avaliação destrutiva de corpos-de-prova amostrados e especificamente preparados para esse fim. Essa prática pode introduzir variabilidade adicional nos resultados em função de fatores como amostragem inadequada ou problemas na confecção do corpo-de-prova.

De acordo com Plessey Telecommunications (citado por CARREIRA, 2003), em 1958 institutos de pesquisas em madeira descobriram que a sua resistência e rigidez à flexão são altamente correlacionadas. Verificaram que a rigidez (módulo de elasticidade - MOE) de uma peça de madeira serrada pode ser forte indicador de sua resistência (módulo de ruptura - MOR).

É possível, assim, uma caracterização eficaz por meio de métodos não destrutivos, nos quais não é necessária a extração de corpos-de-prova, pois a avaliação é feita na própria peça ou estrutura (ROSS et al., 1998).
Ross e Pellerin (1994) definiram como a avaliação de material por meio de métodos não destrutivos como ciência de identificar as propriedades físicas e mecânicas das peças sem alteração das suas propriedades. Tais avaliações devem fornecer informações precisas das propriedades e do desempenho do material.

Para a classificação estrutural de peças de madeira por meio de métodos não destrutivos são, dessa forma, utilizados os métodos visual e mecânico. Na classificação visual da madeira, o classificador examina cada peça e limita o tipo, localização e tamanho dos vários defeitos que podem afetar a resistência estrutural. A classificação mecânica consiste em determinar o módulo de elasticidade longitudinal das lâminas por um meio não destrutivo. Entre os métodos empregados para a classificação estrutural, os mais importantes são a flexão estática, “machine stress rating” (MSR), método da vibração transversal, “stress wave method” e ultrassom.

Entre as diversas técnicas empregadas de classificação de madeira, destaca-se o Stress Wave, que é um método de emissão de ondas de tensão (impacto). A velocidade de propagação de uma onda de tensão induzida e sua atenuação no material são os principais parâmetros analisados nesta técnica (TARGA et al., 2005).

O objetivo do estudo foi estabelecer uma correlação entre os métodos estático e dinâmico de classificação de vigas de madeira laminada colada voltados à construção civil e habitacional, de modo que todas as vigas a serem utilizadas em estruturas possam ser ensaiadas por meio de um método não destrutivo, aproximando-se do valor real do módulo de elasticidade da viga. Para tanto, procurou-se confeccionar as vigas de acordo com o processo de classificação da madeira pelo método visual, o qual é normalmente utilizado.

\section{MATERIAL E MÉTODOS}

\subsection{Caracterização das vigas}

Para a confecção das vigas estruturais de madeira laminada colada (MLC) foram utilizadas 272 peças de madeira serrada de Pinus taeda provenientes de reflorestamentos da Empresa Battistella, as quais apresentavam inicialmente $32 \mathrm{~mm}$ x $128 \mathrm{~mm}$ x $2.050 \mathrm{~mm}$ de dimensões nominais e teor de umidade médio de $12 \%$. O adesivo utilizado nas emendas dentadas, bem como na colagem das lamelas face, a face foi a resorcina fenolformaldeído (RFF). 
O experimento envolveu a confecção de 10 vigas estruturais que apresentavam $3.100 \mathrm{~mm}$ de comprimento, $122 \mathrm{~mm}$ de largura e $156 \mathrm{~mm}$ de altura. As vigas foram compostas por seis peças de madeira serrada aplainadas com $26 \mathrm{~mm}$ de espessura e emendadas até atingir o comprimento desejado.

A análise estatística dos dados coletados nos ensaios foi realizada por meio da análise de regressão para o estabelecimento da equação de ajuste de correlação, pois os objetivos principais deste estudo eram medir o grau de relacionamento entre os dois métodos de obtenção do Módulo de Elasticidade (MOE) e descrever essa relação através de uma equação matemática.

\subsection{Processo de confecção das vigas estruturais}

Todas as peças de madeira serrada que fizeram parte do estudo passaram inicialmente pelo processo de pré-bitolamento em uma plaina, com o objetivo de facilitar a identificação dos defeitos na classificação visual das peças.

Os processos de destopo e classificação foram desenvolvidos conjuntamente. A classificação das peças foi com base na metodologia utilizada rotineiramente pela empresa, a qual é embasada em um estudo desenvolvido por Carreira (2003), que utilizou os métodos de classificação do "Southern Pine Inspection Bureau” (SPIB) de 1994 e 1999, que limitam a presença de defeitos como nós, rachaduras, esmoado e empenamentos; além de agrupar as peças de acordo com a densidade; tendo em vista que madeira mais homogênea, no que diz respeito à sua densidade no interior do tronco, poderá se comportar melhor nas operações de processamento e refletir maior uniformidade nas demais propriedades tecnológicas. As peças de madeira com menor variação de densidade são adequadas para utilizações que exigem material homogêneo e com menor variabilidade nas propriedades fisico-mecânicas (OLIVEIRA et al., 2005).

Classificaram-se, assim, visualmente as peças a serem utilizadas nas vigas, observando as seguintes características: densidade (as peças foram classificadas em densa (D) com seis ou mais anéis de crescimento e mais de $1 / 3$ da seção transversal contendo lenho tardio, ou quatro ou mais anéis de crescimento e mais de $1 / 2$ da seção transversal contendo lenho tardio e não densa (ND) para as densidades média e baixa). As peças classificadas como densas foram utilizadas nas camadas externas das vigas e as não densas, nas quatro lamelas internas; presença de defeitos (na classe de madeira densa não foram permitidos defeitos como nó solto, nó tipo gravata, nó firme atravessando a peça em espessura, medula, esmoado e rachaduras, e para a classe de madeira não densa não eram permitidos defeitos como nó de gravata, nó atravessando a peça em espessura, rachaduras e esmoado); e comprimento das peças (além da classificação visual, as peças a serem utilizadas nas extremidades não poderiam ter comprimento inferior a $800 \mathrm{~mm}$ e as do miolo, a $300 \mathrm{~mm}$ ).

Após a classificação da madeira, procedeu-se à emenda das peças, cujo objetivo foi a obtenção de lamelas com $3.100 \mathrm{~mm}$ de comprimento e o menor número possível de emendas. Obteve-se, dessa forma, cerca de cinco emendas dentadas verticais tipo finger joint com $26 \mathrm{~mm}$ de comprimento por lamela, conforme recomendação do "Deutsches Institut für Normung” - DIN-68-140 (1971), que admite comprimento de dentes de 40 a $60 \mathrm{~mm}$ para peças submetidas a grandes cargas.

O procedimento de confecção das emendas foi realizado por uma fresadeira, para a formação dos dentes nas peças de madeira aplainadas. Na sequência, o adesivo RFF foi preparado na proporção de 100 partes de resina para 15 partes de catalisador e aplicado nas emendas com o auxílio de um pincel; nessa etapa, procurou-se aplicar o adesivo de forma rápida para evitar alterações na sua viscosidade e de não ultrapassar o tempo em aberto recomendado pelo fabricante da resina. Depois, procedeu-se à emenda das peças para a formação da lamela através de uma emendadeira automática. A pressão aplicada foi suficiente para que no ponto de encontro dos dentes de duas peças ocorresse a penetração do adesivo na madeira e a união dos dentes das extremidades de duas peças.

\subsection{Determinação do módulo de elasticidade dinâmico das lamelas por emissão de ondas acústicas}

Com a confecção das lamelas, procedeu-se à identificação destas conforme a sua classificação (densa e não densa) e por ordem numérica dentro de cada grupo de lamelas. Cada lamela, independentemente da sua classificação foi mensurada com o auxílio de uma trena e um paquímetro e pesada. Desta forma, obteve-se a massa específica aparente das lamelas a $12 \%$ de umidade (conforme determinação através de aparelhos baseados na resistência elétrica), que é uma variável de utilização para cálculo do MOE pelo processo dinâmico utilizado no estudo.

R. Árvore, Viçosa-MG, v.34, n.2, p.345-354, 2010 
O “Stress Wave Timer” (SWT), Modelo 239A, da Metriguard é um equipamento composto por dois transdutores acelerômetros dispostos sobre o material a ser medido e um relógio registrador da velocidade da onda. O processo de medição por meio desse equipamento consistiu na disposição da lamela entre os dois sensores com vão livre de $3 \mathrm{~m}$; zerando-se o relógio registrador e, liberando um pêndulo metálico que entra em choque com o sensor que emite a onda na face transversal da lamela, fazendo que a onda percorra a lamela longitudinalmente até o receptor. Dessa forma, determinou-se a velocidade de propagação da onda. O MOE dinâmico das lamelas foi calculado pela equação 1 .

$$
M O E_{d}=\frac{V \times M E_{12 \%}}{A}
$$

em que:

MOEd = módulo de elasticidade dinâmico (MPa); $\mathrm{V}=$ velocidade de propagação da onda $(\mathrm{cm} / \mathrm{s})$; $\mathrm{ME}_{12 \%}=$ massa específica a $12 \%$ de umidade $\left(\mathrm{g} / \mathrm{cm}^{3}\right)$; e A = aceleração da gravidade $\left(9,80 \mathrm{~m} / \mathrm{s}^{2}\right)$.

\subsection{Composição das vigas}

Após a disposição das lamelas na viga de acordo com as classes de densidade e a distância entre as emendas, efetuou-se a aplicação do adesivo pelo sistema de rolos, em uma linha de cola dupla de $500 \mathrm{~g} / \mathrm{m}^{2}$, onde a homogeneização do adesivo foi feita na mesma proporção da utilizada nas emendas “finger joint”; portanto, prepararam-se 9.500 g de adesivo, sendo 8.261 g de resina e $1.240 \mathrm{~g}$ de catalisador.

$\mathrm{Na}$ etapa de prensagem, as vigas foram colocadas à temperatura ambiente com pressões de $142,76 \mathrm{kgf} / \mathrm{cm}^{2}$ e $122,37 \mathrm{kgf} / \mathrm{cm}^{2}$, para as partes superior e lateral do equipamento, respectivamente. Desse modo, o processo foi concluído após $12 \mathrm{~h}$ de exposição às variáveis do ciclo de prensa.

\subsection{Ensaios de resistência estrutural}

As lâminas externas, de acordo com Bodig e Jayne (1982), contribuem mais sobre o valor do módulo de elasticidade efetivo da viga que aquelas lâminas colocadas próximas à linha neutra. Nesse caso, o posicionamento das lâminas de maior resistência, ou de maior módulo de elasticidade próxima à superfície, torna-se interessante.
O valor do MOE dinâmico das vigas foi, dessa forma, estimado com base na distribuição das lamelas ao longo do composto, compreendendo seis camadas de lamelas, sendo cada uma com a respectiva identificação e o valor de módulo de elasticidade dinâmico individual. Assim, procedeu-se ao cálculo do MOE das vigas (equação 2), de acordo com as fórmulas apresentadas por Bodig e Jayne (1982).

$$
\operatorname{MOE}_{e}=\frac{2}{I} \times \sum_{i=1}^{n} \operatorname{MOEt}^{i} \times I^{i}
$$

em que:

MOEe = módulo de elasticidade efetivo (MPa);

MOEt $\mathrm{t}^{\mathrm{i}}$ = módulo de elasticidade da i-ésima lâmina na direção longitudinal (MPa);

$\mathrm{I}^{\mathrm{i}}$ = momento de inércia da seção da i-ésima lâmina, em relação à linha neutra da viga $\left(\mathrm{mm}^{2}\right)$;

I = momento de inércia de toda a seção da viga ( $\left(\mathrm{mm}^{4}\right)$; e

$\mathrm{n}=$ metade do número total de lâminas.

O cálculo do momento de inércia de cada lâmina em relação à linha neutra foi obtida pela equação 3,

$$
I^{i}=I_{o}^{i}+A^{i} \times\left(d^{i}\right)^{2}
$$

em que:

I $^{\mathrm{i}}=$ momento de inércia da i-ésima lâmina em relação à linha neutra da vigas $\left(\mathrm{mm}^{3}\right)$;

$\mathrm{I}_{\mathrm{o}}{ }^{\mathrm{i}}=$ momento de inércia da i-ésima lâmina em relação à sua linha neutra, baricentral $\left(\mathrm{mm}^{4}\right)$;

$\mathrm{A}^{\mathrm{i}}$ = área da seção transversal da i-ésima lâmina $\left(\mathrm{mm}^{2}\right) ; \mathrm{e}$

$\mathrm{d}^{\mathrm{i}}=$ distância entre o plano baricentral da viga laminada e a i-ésima lâmina (mm).

Inserindo o cálculo do momento de inércia de cada lâmina (equação 3) na equação 2 (MOE dinâmico das vigas), tem-se a equação 4, que detalha todos as variáveis a serem calculadas para a obtenção da variável de interesse.

$$
\operatorname{MOE}_{e}=\frac{2}{I} \times \sum_{i=1}^{n} \operatorname{MOEt}^{i} x\left(I_{o}^{i}+A^{i} \times\left(d^{i}\right)^{2}\right)
$$

Na realização do ensaio destrutivo das vigas para a obtenção dos valores de MOE foi utilizado como referência o método descrito pela seção 4 da 
“AMERICAN SOCIETY FOR TESTING MATERIALS” -ASTM D-198 (1996), o qual visa à determinação das propriedades de flexão para vigas estruturais feitas de madeira sólida ou laminada.

Para a realização deste ensaio, utilizou-se uma máquina universal de ensaios (EMIC DL - 30000). À distância entre os pontos de apoio foi de $2.700 \mathrm{~mm}$, sendo o espaço entre o ponto de reação e o ponto de aplicação de carga de $900 \mathrm{~mm}$, conforme prescrito na norma ASTM D-198 (1996), que determina para a avaliação de propriedade de flexão um comprimento da zona de cisalhamento na razão entre 5:1 a 12:1, o qual corresponde à razão entre a distância entre o ponto de aplicação da carga e o ponto de reação mais próximo e a altura da viga; assim, na razão 900 para 122 obtém-se 7,4:1. Calculadas as distâncias na zona de cisalhamento, determinou-se a distância entre os dois pontos de aplicação de carga, que vem a ser a zona de flexão que foi também de $900 \mathrm{~mm}$.

Para a determinação da deformação da viga ao longo do ensaio, utilizou-se um deflectômetro com capacidade de variação de deformação de $2,5 \mathrm{~cm}$ a partir do ponto inicial do ensaio. O deflectômetro foi posicionado na linha neutra no meio da viga, sendo fixado em uma barra de alumínio conhecida como "yoke”, a qual estava fixada na linha neutra em dois pontos distanciados em 700 mm (L1), ou seja, 350 mm para cada lado do meio da viga.

Determinadas as distâncias entre os pontos de reação e os pontos de aplicação de carga, procedeu-se aos ensaios. O módulo de elasticidade da viga no ensaio destrutivo foi calculado ao considerar a diferença de deformação entre 40\% e 10\% da força máxima, adotandose para cálculo deste parâmetro a Norma Europeia EN 789 (1995). Dessa forma, aplicou-se a equação 5.

$$
\begin{aligned}
& \text { em que: } \\
& \text { em }=\frac{\left(F_{40 \%}-F_{10 \%}\right) \times L_{1}^{2} \times L_{2}}{16 \times\left(d e f_{40 \%}-d e f_{10 \%}\right) \times I_{o}}
\end{aligned}
$$

MOE = módulo de elasticidade (MPa);

$\mathrm{F}_{40 \%}=$ carga correspondentea $40 \%$ da carga máxima(N);

$\mathrm{F}_{10 \%}=$ carga correspondentea $10 \%$ da carga máxima(N);

L1 = distância entre os pontos de apoio do “yoke” (mm);

L2 = metade do comprimento da zona de cisalhamento (mm);

$\operatorname{def}_{40 \%}=$ deformação correspondente a $40 \%$ da carga máxima (mm);

def $_{10 \%}=$ deformação correspondente a $10 \%$ da carga máxima (mm); e

$\mathrm{I}_{\mathrm{o}}=$ momento de inércia baricentral $\left(\mathrm{mm}^{4}\right)$, sendo ((base $\mathrm{X}$ altura $\left.\left.^{3}\right) / 12\right)$.

\section{RESULTADOS}

\subsection{Módulo de elasticidade dinâmico das lamelas}

A Tabela 1 apresenta os valores do MOE dinâmico das lamelas, em que se observa que a de maior resistência deveria estar posicionada na camada inferior da viga, a segunda na parte superior, a terceira na segunda posição, no sentido de baixo para cima, e assim sucessivamente. Desse modo, observa-se que nas 10 vigas analisadas, nenhuma apresentou distribuição correta das lamelas, o que pode diminuir a resistência da viga.

Tabela 1 - Valores individuais de MOE dinâmico para as lamelas. Table 1 - Individual values for dynamic MOE for lamellas.

\begin{tabular}{|c|c|c|c|c|c|c|c|c|c|}
\hline$\overline{\text { Viga }}$ & Lamela & $\begin{array}{c}\text { Massa } \\
\text { Específica } \\
\text { aparente } \\
\left(\mathrm{kg} / \mathrm{m}^{3}\right)\end{array}$ & $\begin{array}{c}\text { Velocidade } \\
(\mathrm{cm} / \mathrm{s})\end{array}$ & $\begin{array}{c}\text { MOE } \\
(\mathrm{MPa})\end{array}$ & Viga & Lamela & $\begin{array}{c}\text { Densidade } \\
\left(\mathrm{kg} / \mathrm{m}^{3}\right)\end{array}$ & $\begin{array}{l}\text { Velocidade } \\
\text { (cm/s) }\end{array}$ & $\begin{array}{c}\text { MOE } \\
\text { (MPa) }\end{array}$ \\
\hline \multirow[t]{6}{*}{01} & $45 S S$ & 469 & 402.145 & 7.738 & 06 & $62 \mathrm{SS}$ & 438 & 450.450 & 9.057 \\
\hline & $91 \mathrm{M} 1$ & 420 & 393.185 & 6.628 & & 108M1 & 422 & 404.313 & 7.042 \\
\hline & $71 \mathrm{M} 2$ & 418 & 411.523 & 7.225 & & 98M2 & 402 & 379.267 & 5.899 \\
\hline & 85M3 & 398 & 339.367 & 4.675 & & 110M3 & 418 & 330.033 & 4.647 \\
\hline & $102 \mathrm{M} 4$ & 398 & 400.534 & 6.512 & & $111 \mathrm{M} 4$ & 413 & 365.854 & 5.641 \\
\hline & $47 \mathrm{SI}$ & 420 & 462.250 & 9.161 & & 66SI & 438 & 427.960 & 8.175 \\
\hline
\end{tabular}


Tabela 1 - Cont.

\begin{tabular}{|c|c|c|c|c|c|c|c|c|c|}
\hline \multirow[t]{6}{*}{02} & 59SS & 455 & 376.412 & 6.574 & \multirow[t]{6}{*}{07} & 31SS & 495 & 332.594 & 5.580 \\
\hline & 106M1 & 396 & 394.737 & 6.292 & & 76M1 & 440 & 304.260 & 4.151 \\
\hline & 69M2 & 446 & 371.747 & 6.283 & & 93M2 & 431 & 396.825 & 6.931 \\
\hline & 77M3 & 420 & 410.397 & 7.221 & & 79M3 & 383 & 393.701 & 6.050 \\
\hline & 74M4 & 418 & 405.954 & 7.031 & & 87M4 & 404 & 389.105 & 6.240 \\
\hline & 46SI & 422 & 427.960 & 7.890 & & $23 S I$ & 546 & 413.793 & 9.543 \\
\hline \multirow[t]{6}{*}{03} & $48 S S$ & 483 & 335.196 & 5.540 & \multirow[t]{6}{*}{08} & 43SS & 453 & 360.144 & 5.991 \\
\hline & 86M1 & 423 & 426.136 & 7.842 & & 103M1 & 419 & 369.458 & 5.838 \\
\hline & 107M2 & 427 & 418.410 & 7.633 & & $82 \mathrm{M} 2$ & 416 & 385.604 & 6.313 \\
\hline & 68M3 & 378 & 369.458 & 5.257 & & $105 \mathrm{M} 3$ & 449 & 334.076 & 5.109 \\
\hline & 73M4 & 389 & 386.598 & 5.927 & & 88M4 & 441 & 388.601 & 6.788 \\
\hline & 64SI & 442 & 468.750 & 9.899 & & 33SI & 467 & 444.444 & 9.410 \\
\hline \multirow[t]{6}{*}{04} & 35SS & 435 & 350.877 & 5.457 & \multirow[t]{6}{*}{09} & $65 S S$ & 452 & 425.532 & 8.345 \\
\hline & 75M1 & 381 & 388.098 & 5.848 & & 92M1 & 408 & 389.105 & 6.302 \\
\hline & 72M2 & 467 & 382.653 & 6.976 & & $95 \mathrm{M} 2$ & 425 & 340.522 & 5.031 \\
\hline & 101M3 & 407 & 389.105 & 6.287 & & 83M3 & 505 & 435.414 & 9.760 \\
\hline & 100M4 & 488 & 468.750 & 10.947 & & 97M4 & 428 & 404.858 & 7.163 \\
\hline & 41SI & 443 & 402.145 & 7.302 & & 39SI & 477 & 409.277 & 7.633 \\
\hline \multirow[t]{6}{*}{05} & 27SS & 477 & 389.610 & 7.390 & \multirow[t]{6}{*}{10} & $42 S S$ & 481 & 412.088 & 8.337 \\
\hline & 84M1 & 449 & 361.011 & 5.966 & & 89M1 & 430 & 364.520 & 5.828 \\
\hline & 90M2 & 394 & 413.793 & 6.879 & & 70M2 & 388 & 401.606 & 6.379 \\
\hline & 78M3 & 385 & 414.365 & 6.738 & & 104M3 & 398 & 406.504 & 6.707 \\
\hline & 81M4 & 388 & 373.134 & 5.507 & & $80 \mathrm{M} 4$ & 389 & 375.000 & 5.577 \\
\hline & $24 \mathrm{SI}$ & 459 & 346.420 & 5.618 & & 63SI & 473 & 405.954 & 7.954 \\
\hline
\end{tabular}

SS - lamela superior da viga; M - lamela do miolo em ordem crescente, representando as lamelas dispostas de cima para baixo na viga; e SI - lamela inferior da viga.

\subsection{Módulo de elasticidade das vigas de madeira laminada colada}

A partir da determinação do MOE dinâmico individual das lamelas, foi estimado o módulo de elasticidade dinâmico da viga com base na classificação visual realizada pela empresa e também por meio da distribuição das lamelas de acordo com a qualidade de resistência desejada para a realização de comparações (Tabela 2); pois, de acordo com Zangiácomo (2003), as propriedades de rigidez de vigas de MLC, obtidas nos ensaios de flexão estática, podem ser influenciadas pela disposição das lâminas ao longo da altura da seção transversal. Vigas com distribuição não aleatória de lâminas podem apresentar propriedades de rigidez superiores às de vigas montadas com distribuição aleatória de lâminas.

Na Tabela 3, evidencia-se, através da Análise da Variância, que existe diferença significativa nos valores de módulo de elasticidade dinâmico entre o método aleatório de distribuição das lamelas ao longo da viga e o não aleatório, demonstrando a importância em se fazer uma classificação por rigidez das lamelas antes de serem dispostas na viga.
Tabela 2- Valores de módulo de elasticidade dinâmico e estático das vigas de MLC.

Table 2 - Values of modulus of elasticity of static and dynamic glulam beam.

\begin{tabular}{lccc}
\hline Viga & \multicolumn{2}{c}{$\begin{array}{c}\text { MOE Dinâmico } \\
(\mathrm{MPa})\end{array}$} & $\begin{array}{c}\text { MOE Estático } \\
\text { (MPa) }\end{array}$ \\
\cline { 2 - 3 } & Aleatório & Não-Aleatório & \\
\hline 1 & 7.870 & 7.949 & 14.298 \\
2 & 7.054 & 7.309 & 17.486 \\
3 & 7.455 & 8.196 & 15.096 \\
4 & 6.912 & 8.350 & 15.901 \\
5 & 6.316 & 6.714 & 14.275 \\
6 & 7.902 & 7.931 & 17.078 \\
7 & 6.908 & 7.570 & 14.156 \\
8 & 7.267 & 7.497 & 14.366 \\
9 & 7.642 & 8.498 & 17.374 \\
10 & 7.453 & 7.640 & 15.858 \\
Média & 7.2780 & 7.765 & 15.589 \\
Variância & 242.321 & 284.966 & 1.817 .467 \\
Desvio Padrão & 492 & 534 & 1348 \\
Valor Máximo & 7.902 & 8.498 & 17.486 \\
Valor Mínimo & 6.316 & 6.714 & 14.156 \\
\hline
\end{tabular}

MOE dinâmico aleatório: por meio do SWT, conforme distribuição utilizada pela empresa. MOE dinâmico não aleatório: por meio do SWT, conforme distribuição por MOE em cada lamela. MOE estático: variável determinada por meio destrutivo em Máquina Universal de Ensaios. 
Tabela 3 - Análise de variância do módulo de elasticidade aleatório e não aleatório.

Table 3 - Analysis of variance for random and non-random modulus of elasticity.

\begin{tabular}{cccccc}
\hline Fonte de variação & GL & SQ & QM & F & Valor- $P$ \\
\hline Entre grupos & 1 & 1188281,25 & 1188281,25 & 4,507151418 & 0,0478786 \\
Resíduo & 18 & 4745583,3 & 263643,5167 & & \\
Total & 19 & 5933864,55 & & & \\
\hline
\end{tabular}

SQ: soma de quadrados; GL: grau de liberdade; QM: quadrado médio; e F: valor de F calculado.

\subsection{Método dinâmico $X$ método estático}

Efetuando uma análise comparativa entre os métodos de obtenção do MOE dinâmico e estático, verificou-se que a correlação entre as variáveis foi muito baixa, pois o coeficiente de encontrado foi de 0,1170. Mesmo assim, desenvolveu-se uma análise de regressão (Figura 1), em que se observa a dispersão dos valores encontrados nos ensaios.

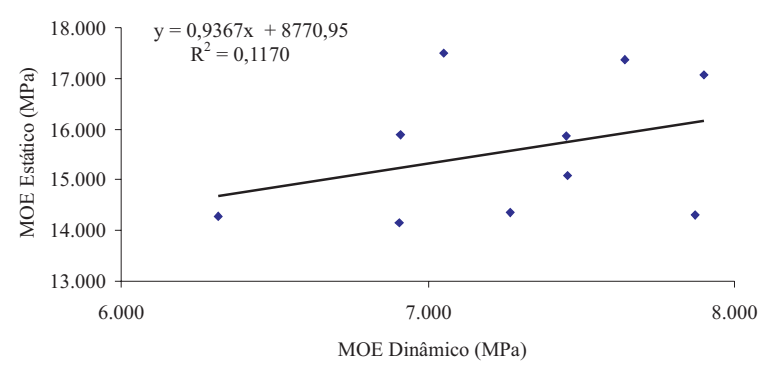

Figura 1 - Correlação entre os métodos estático e dinâmico de obtenção do MOE.

Figure 1 - Correlation between static and dynamic methods getting the MOE.

\section{DISCUSSÃO}

\subsection{Módulo de elasticidade dinâmico das lamelas}

O método não destrutivo de avaliação das propriedades de resistência da madeira por meio do Stress Wave Timer depende diretamente da velocidade de propagação da onda ao longo da peça ensaiada e da densidade do material. Quanto à velocidade de propagação da onda, quanto maior a velocidade, maior o módulo de elasticidade da peça analisada, mantendose as demais variáveis inalteradas. Como pode ser observado na Tabela 1, a lamela denominada 47SI (Superfície Inferior) da viga 1 e na 77M3 (Miolo) da viga 2 apresentam densidade igual a $420 \mathrm{~kg} / \mathrm{m}^{3}$, velocidades de $462.250 \mathrm{~cm} / \mathrm{s}$ e $410.397 \mathrm{~cm} / \mathrm{s}$ e, consequentemente, MOE diferenciado de 9.161 MPa e 7.2201 MPa, respectivamente.
Ao mesmo tempo, a velocidade de propagação da onda também é influenciada pela quantidade de material lenhoso. Assim, de modo geral, quanto maior a densidade, maior o módulo de elasticidade, tendo em vista que o módulo de elasticidade dinâmico é uma função do quadrado da velocidade de propagação da onda e da densidade.

Pode-se, dessa forma, atribuir os diferentes índices de velocidade obtidos nas vigas à presença de defeitos naturais como presença de nós, à quantidade de encaixes utilizados nas emendas dentadas tipo finger joit e ao adesivo utilizado na junção.

Com relação à densidade, pode-se destacar a influência da espécie, do teor de umidade, da largura dos anéis de crescimento, da posição de retirada da peça ao longo do fuste da árvore, da porcentagem de lenho inicial e tardio e da diferenciação entre lenho juvenil e adulto, além de influências externas. Dessa forma, evidencia-se no cálculo da massa específica aparente (Tabela 1) grande heterogeneidade de valores com amplitude entre as peças de $378 \mathrm{~kg} / \mathrm{m}^{3}$ e $546 \mathrm{~kg} / \mathrm{m}^{3}$. Essa amplitude de variação é certamente derivada da origem das peças destinadas ao estudo, que contempla uma série de condições, em que se destacam a idade das árvores, a posição de retiradas das peças e as influências externas.

A idade das árvores reflete a diferenciação entre os lenhos juvenil e adulto, em que peças estruturais que contenham determinada quantidade de lenho juvenil apresentam classes de resistência inferiores, sendo esse o motivo pelo qual as diferenças entre as propriedades dos lenhos são importantes para a utilização da madeira (MCALISTEReCLARK, 1991; GEIMER etal., 1997, ambos citados por BALLARIN e PALMA, 2003). Como neste estudo não houve classificação da madeira direcionada ao uso estrutural, obtiveram-se peças de diversas porções da árvore e, consequentemente, de diversas classes. Quanto às influências externas, destacam-se as condições de crescimento e os métodos silviculturais aplicados.

R. Árvore, Viçosa-MG, v.34, n.2, p.345-354, 2010 
A forma de aplicação da onda poderia ser fator que diferenciasse a sua propagação, mas, durante a execução dos ensaios, esta se manteve a mesma constante, colocando sempre o pêndulo de aplicação a uma mesma distância da peça, o que gera uma mesma intensidade de aplicação da onda em todas as peças ensaiadas.

A distribuição das lamelas em dois grupos de resistência (densa e não densa) na viga de MLC pelo método não destrutivo é fator determinante na resistência da viga, tendo em vista que as lamelas com maiores valores de MOE deveriam ser dispostas nas regiões mais solicitadas da viga, ou seja, na zona de tração e compressão. Dessa forma, verifica-se que somente a análise visual com base na contagem de anéis de crescimento e na ocorrência de defeitos naturais das lamelas não foi suficiente para se alcançarem os maiores valores de MOE na viga, sendo necessária a implementação de sistemas de classificação dinâmicos em todas as lamelas, para aumentar o módulo de elasticidade da viga.

O sistema de classificação por meio do Stress Wave Method é simples, prático e de resultado imediato, podendo ser utilizado em qualquer parte da empresa, seja na floresta, seja na indústria, tendo em vista que é um equipamento leve e portátil, podendo determinar a velocidade de propagação tanto em árvores quanto em peças de madeira serrada. O conjunto desses fatores torna o sistema atraente diante dos outros métodos não destrutivos, que são de grande porte, alto investimento e manutenção, contanto com "softwares" sofisticados.

Em estudo realizado por Fagundes e Szücs (1998), notou-se que após a classificação foram estabelecidas três classes de vigas com módulos de elasticidade maiores, médios e menores, os quais foram distribuídos em cinco modelos de vigas; os resultados do experimento demonstraram que não houve diferença estatística na resistência das vigas analisadas, mas a dispersão dos valores de MOE foi pequena, de 7.581 MPa a 7.630 MPa. Entretanto, neste estudo a dispersão dos valores de MOE dinâmico foi de $4.151 \mathrm{MPa}$ a $10.947 \mathrm{MPa}$. A amplitude dos valores de MOE dinâmico encontrados neste estudo certamente não apresentaria as mesmas considerações se fosse aplicado ao estudo comparativo, reforçando a necessidade de uma classificação não destrutiva durante a composição das vigas estruturais de madeira laminada colada pelas lamelas emendadas.
Evidencia-se, dessa forma, que quanto maior o número de grupos de resistência à atividade for subdividido, maior será a probabilidade de se aumentar a resistência da viga.

\subsection{Módulo de elasticidade das vigas de madeira laminada colada}

Ao analisar a Tabela 2, observou-se que em todas as vigas com classificação e distribuição adequada das lamelas (não aleatória)foi obtido ganho médio significativo (Tabela 3) de resistência de 6\%, mas pode atingir $17 \%$ como na viga 4 , em que se obtiveram 6.912 MPa, separando apenas as lamelas em duas classes de resistência pelo método visual e $8.350 \mathrm{MPa}$ com MOE estimado pelo Stress Wave, distribuindo-se as peças por meio da resistência encontrada pelo processo, tendo em vista que as regiões mais solicitadas da viga recebiam as lamelas com maior módulo de elasticidade.

Neste estudo, optou-se pela divisão das peças em duas classes de qualidade, densa e não-densa, sem ter a preocupação com os valores de resistência dentro das classes. Assim, a resistência foi reduzida quando comparada com o que se poderia obter de resistência do material pela distribuição adequada das lamelas.

\subsection{Método dinâmico x método estático}

Evidenciou-se que MOE dinâmico explica somente $11,70 \%$ do estático, sendo o restante da porcentagem até atingir 100\% derivado de outras variáveis como matéria-prima, condições de confecção das vigas e procedimentos utilizados nos ensaios. Com relação aos procedimentos de ensaio, foram utilizadas formas diferenciadas de obtenção do MOE, em que o dinâmico foi embasado no MOE individual de cada lamela, estimando-se o MOE da viga inteira e o estático com aplicação dupla de carga na viga inteira, através do método não destrutivo, e neste segundo método contava-se com a presença do adesivo unindo as lamelas face a face. Dessa forma, mesmo não havendo relação direta entre o MOE estimado da viga e o real, reforça-se a importância dos ensaios não destrutivos, pois, classificando a madeira em grupos de resistência, privilegia-se o aumento da resistência das vigas durante a sua utilização na estrutura e, ou, durante os ensaios mecânicos em laboratório, assegurando melhor aproveitamento da madeira e maior segurança das vigas em uso. 
Andrigheto et al. (2006) realizaram ensaios de flexão estática em madeira laminada colada de Pinus spp. com $3.150 \mathrm{~mm}$ de comprimentoe $315 \mathrm{~mm}$ de altura, sendo composta por 12 lâminas classificadas de acordo com a análise visual e as propriedades físico-mecânicas da madeira. Os resultados demonstraram nas vigas com $1 / 4$ de lâminas com qualidade superior, MOE médio de $12.695 \mathrm{MPa}$; nas vigas com 1/6 de lâminas com qualidade superior, MOE de 10.252 MPa; já quando foram utilizadas lâminas invertidas nas regiões de maior esforço, o MOE foi de $11.685 \mathrm{MPa}$.

Comparando os resultados deste trabalho com os do estudo mencionado, verificou-se que foram superiores na variável módulo de elasticidade e que o menor valor deste estudo (14.156 MPa) foi superior ao encontrado pelos pesquisadores citados. Assim, pode-se dizer que as vigas apresentaram menor deformabilidade e maior resistência, consequentemente melhores as características da madeira para uso estrutural. Dessa forma, mesmo com os expressivos resultados, deve-se enfatizar que os valores de MOE encontrados nas vigas de MLC podem ser aumentados com o efetivo controle dos níveis de defeitos da madeira admitidos para a classificação.

\section{CONCLUSÕES}

O sistema de classificação visual utilizado na seleção de peças de madeira para a confecção de vigas estruturais de madeira laminada colada (MLC) foi insuficiente para se atingirem os valores máximos de módulo de elasticidade das vigas.

O processo visual de classificação através da análise dos defeitos e proporção de lenho tardio na seção transversal da peça pode ser utilizado nas operações de destopo e pré-classificação das peças para a composição das lamelas, reduzindo o custo da classificação e aumentando o rendimento da operação.

As variações dos valores de módulo de elasticidade dinâmico das lamelas foram afetadas diretamente pela amplitude dos valores de massa específica e de velocidade de propagação da onda.

O posicionamento correto das lamelas por meio de métodos dinâmicos de classificação como o Stress Wave Method teve como consequência o aumento do módulo de elasticidade.

Neste estudo, evidenciou-se que houve baixa correlação entre o módulo de elasticidade dinâmico e estático das vigas de madeira laminada colada, não sendo possível a elaboração de uma equação adequada de correlação entre as diferentes formas de obtenção da variável.

\section{REFERÊNCIAS}

AMERICAN SOCIETY FOR TESTING MATERIALS

- ASTM. ASTM D-198. Annual Book of ASTM Standards. Section 4 - Construction, v. 04.10 Wood. Philadelphia: 1998.p. 57-75.

ANDRIGHETO, R.; SZÜCS, C. A. Estudo comparativo entre madeira laminada colada e madeira laminada colada multicolada. In: EBRAMEM - ENCONTRO BRASILEIRO EM MADEIRAS E EM ESTRUTURAS DE MADEIRA, 10., 2006, São Pedro. Anais... São Pedro: 2006.

BALLARIN, A. W.; PALMA, H. A. L. Propriedades de resistência e rigidez da madeira juvenil e adulta de Pinus taeda L.. Revista Árvore, v.27, n.3, p.371-380, 2003.

BODIG, J.; JAYNE, B. A. Mechanics of wood and wood composities. New York: Van Nostrand Reinhold, 1982.

CARREIRA, M. R. Critérios para classificação visual de peças estruturais de Pinus sp. 2003. 182f. Dissertação (Mestrado) Universidade de São Paulo, São Carlos, 2003.

DEUTSCHES INSTITUT FÜR NOMUNG. DIN 68 140 - Wood Finger - Jointing. Berlim: 1971.

FAGUNDES, G. S.; SZÜCS, C. A. Composição racional de vigas de madeira laminada colada de Pinus. In: EBRAMEM - ENCONTRO BRASILEIRO EM MADEIRAS E EM ESTRUTURAS DE MADEIRA, 6., 1998, Florianópolis. Anais... Florianópolis: 1998. p. 277-288. 1998.

OLIVEIRA, J. T. S.; HELLMEISTER, J. C.; TOMAZELLO FILHO, M. Variação do teor de umidade e da densidade básica na madeira de sete espécies de eucalipto. Revista Árvore, v.29, n.1, p.115-127, 2005.

ROSS, R. J. et al. Nondestructive evaluation of wood. Madison: Forest Products Laboratory, 1998. p.14-19.

ROSS, R. J.; PELLERIN, R. Nondestructive testing for assessing wood members in structures: a review. Madison: Department of Agriculture - Forest Service, Forest Products Laboratory, 1994. p.28.

R. Árvore, Viçosa-MG, v.34, n.2, p.345-354, 2010 
TARGA, L. A.; BALLARIN, A. W.;

BIAGGIONI, M. A. M. Avaliação do módulo de elasticidade da madeira com uso de método não-destrutivo de vibração transversal.

Engenharia Agrícola, v.25, n.2, p.291299, 2005.
ZANGIÁCOMO, A. L. Emprego de espécies tropicais alternativas na produção de elementos estruturais de madeira laminada colada. 2003. 82f. Dissertação (Mestrado) - Universidade de São Paulo, São Carlos, 2003. 